\title{
Large Intestine
}

National Cancer Institute

\section{Source}

National Cancer Institute. Large Intestine. NCI Thesaurus. Code C12379.

A muscular tube that extends from the end of the small intestine to the anus. 